\title{
The Role of Music in the Design Process with Children
}

\author{
Ruut Tikkanen and Netta Iivari \\ Department of Information Processing Science, University of Oulu \\ P.O. Box 3000, 90014 Oulu, Finland \\ \{Ruut.tikkanen, netta.iivari\}@oulu.fi
}

\begin{abstract}
Music and other art based methods should play a significant role in the HCI field when designing with children, taking the developmental stage of the children into consideration. Music has been neglected in the design process in HCI research, while there is a lot of meaningful research in social and educational studies. HCI research has concentrated more on technological products and technological needs of special education, bringing up music as an important part of media too. In this paper we emphasize the versatile role of music during the design process with preschool children. We describe three different workshops identifying three different roles for music: a contextual role, music as a trigger and music as content. The roles demonstrate numerous possibilities for using music in design workshops and show the usefulness of music in collaborative design with children. HCI research should utilize music in more varied forms during design.
\end{abstract}

Keywords: Preschool children, music, design process.

\section{Introduction}

There are a number of different elements, which should be considered in the child centred interface design. The Human Computer Interaction (HCI) literature concerning children contains a number of perspectives. The literature maintains that children differ from adults. Their world is different. Their skills are still in the developmental stage. On the other hand, children's imagination can offer for adults something that they themselves could not imagine. (See e.g. [9], [10], [12], [20], [42].) Although the development of a child is an individual process, development areas such as motoric, cognitive, social and emotional development can be identified. For example, according to children's cognitive developmental stage theory (see e.g. [36]) children from 5 to 6 years old live early childhood and are in a preoperational stage. Particularly play and imagination as well as different kinds of activities with others of the same age have a big meaning in children's life. According to Hanna and colleagues [20], children of this age are happy to show you what they know, and what they can do on the computer independently. When assessing appeal or engagement, it is important to observe children's behaviour such as sighing, smiling, or sliding under the table. Children of this age often have difficulties in expressing their likes and dislikes in words. [20.] 
Methods used with children usually differ from those used with adults, although some methods intended for adults are applied also with children. It is, nevertheless, recommended that the methods should be such or modified so that they are appropriate for child participants and their developmental stage (e.g. [11], [12], [18], [20], [30], [31], [42]). In the literature on child's development one of the central ideas, from Piaget [36] and Vygotsky [44] is that children perceive the world by playing and singing. That is one scientific basis for using art-oriented methods, which are considered to provide interesting dimensions to user interface design with children (see e.g. [17]). Only very few articles have touched upon the role of music in the design process with children. Furthermore, the studies describe the design process with children, the music being related to the product being designed, not to the design process itself (see [3], [32] [33]). In this study, instead, music plays an important role during the design process. We also argue that music should be utilized in technology design more broadly. Design processes remain only too silent.

This paper examines the variety of roles music may have in the design process with children. This study is an exploratory study of the roles of music, revealing some of those, while more rigorous experiments on the effects of music can be carried out later on, based on and extending the results of this study. The topic is examined in a research project developing a music application for children, together with children. In the research project, numerous innovative workshop sessions have been organized with children (see e.g. [32]), music being in different roles in the workshops. In this paper we describe three different workshops, through which we outline what kind of meanings music may have in the design process with children. To summarize; music had mainly a contextual meaning in the first workshop. The aim was to determine what kinds of ideas children have about musical instruments and producing sounds: what do they build, if they are free to compose their own musical instrument or device? In the second workshop music was combined with emotions. Two music samples were played for children and they drew their thoughts and feelings, listening to music in the background. In the third workshop music had a substantive role. The purpose was to find out what kind of sounds children connect to different pre-given landscapes of the music application being designed.

The paper is structured as follows. The next section reviews the extant literature on children, technology and music. The third section present the research setting and procedure involved in this study. The fourth section outlines the roles of music we identified in our design sessions. The final section summarizes the results, outlines their implications and limitations and identifies a number of paths for future work.

\section{Literature Review}

A short review to different journals and articles on children's technology and music field illustrates that music and children is an important research topic in connection to technology. Technology has provided an opportunity to revise working with music and music teaching already in 1990s. Technology like computers, synthesizers and hypermedia seems to be conceived like a new tool in relation to old craft [43]. 
There are only few music related articles concentrating on describing design process with children in this area. Bar-Ilan and Belous [3], Mazzone and colleagues [32] and McKnight and Read [33] enlarge this topic from three different viewpoints. In the experiments of Bar-Ilan and Belous [3], children act as architects of web directories. The authors advise researchers to include children in the design process, not only designing the interface but designing the content structure as well. McKnight and Read [33] concentrate on the design of a record button, their work being part of designing a musical interface with children. Mazzone and colleagues [32] create a rich background on a general level related to designing with children in the context of a music application, because they have actively worked with children during the design process, but they do not concentrate on the meaning of music in the process. Although music is mentioned in these experiment descriptions, it appears more in the subtext of the design research with children. Also Hartnett and colleagues [22] describe the design and development process of an audio device to stimulate exercise and fitness in children, but the device is designed for children, not with children. None of the articles discuss directly music. Music is addressed in connection to the product, not during the design process.

On the other hand, there is an extensive body of research addressing music, technology and children more generally. This research can be broken up into different areas. First of all, children's technologies including different kind of software and web-based-systems seem to be central in the scientific discussions as well as in practical work. Children are widely perceived as users of different kinds of music software. Music is one area of concern when presenting children's future technologies. There are several kinds of music software, in most cases educational software, discussed, aimed at e.g. for composing [6], [24], for making music [16] for having fun [40] for playing [1], [6], [39], [40], [45], for moving [2], ]22], [46], for interactive communicating [1], [2], [7], [27], [46], for exercising and learning [16], [35] or for performing [45]. There are also several media systems, where music is a big part of the technological entity. Music is also related to other arts or creative media like painting, dancing or architectural planning [2], [3], [40].

Furthermore, music and children are increasingly in the focus of human brain research concerning, for example, music, speech and language processing [25], [26], [29]. Especially children's musical development is taken into consideration in these studies. Closely in relation to technological brain research there is also a research domain of music therapy, which concerns different kinds of technological solutions for the impairments of children in the area of speech and music [5], [21], [25].

Music is generally treated as an important matter. It is a central focus in many research papers as such, or treated as one part of media [27]. For example, the central focus of the research by Beck [4] is the confidence of children to be achieved through nurturing them with music. The significance of music has been showed in many ways and it has significance in many kinds of technologies, although they are not primarily music technologies. Music and its influence to the human brain is an important part of children's development. For example Bresler [8] and Rusinek and Rincon [41] use musical performing when presenting the importance of music. The purpose of most technologies is to support in an appropriate way certain stages of child's development. 
Although there is some research found concerning design process or part of it carried out together with children [3], [32], [33], the designed music product has been the main issue in most of the studies.

Table 1 summarizes the literature review results.

Table 1. Different meanings of music in connection to children and technology

\begin{tabular}{llll}
\hline Aspects & $\begin{array}{l}\text { Music } \\
\text { and } \\
\text { Design }\end{array}$ & $\begin{array}{l}\text { Children's Music } \\
\text { Technologies }\end{array}$ & Music Education \\
\hline $\begin{array}{l}\text { RESEARC- } \\
\text { HERS }\end{array}$ & $\begin{array}{l}\text { Bar-Ilan \& } \\
\text { Belous [3], } \\
\text { Mazzone et }\end{array}$ & $\begin{array}{l}\text { Akiyama [1], Aucouturier \& } \\
\text { Ikegami [2], Berry et al [6], }\end{array}$ & $\begin{array}{l}\text { Beck [4], Benveniste et al } \\
\text { [5], Bresler [8], Fischer \& }\end{array}$ \\
& $\begin{array}{l}\text { al [32], } \\
\text { McKnight }\end{array}$ & [16], Hartnett et al [22], Jennings & $\begin{array}{l}\text { Lau [16], Harris \& Summa- } \\
\text { Chadwick [21], Jennings }\end{array}$ \\
& \& Read & [35], Reynolds [39], Rosenbaum & [24], Jentschke et al [25], \\
& Koelsch et al, [26], Magne \\
& [33] & \& Silver [40], Weinberg et al & et al [29], Rusinek \& \\
& & [45], Zigelbaum et al [46] & Rincon [4]
\end{tabular}

Why music and sound should be introduced as an important issue in the design process? Best knowledge is going to be found undoubtedly from the area of music research. Several studies especially in the area of music education argue for the significance of music for children, being based on the developmental research theories. According to Flohr [17] sound is among the earliest stimuli to have some form of meaning for the human being. According to him, music clearly belongs in the young child's life as a distinct discipline and as an art form. The value of music for children has been divided into intrinsic and extrinsic musical benefits. According to several music educationis [14], [15], [34], [37], [38], the intrinsic benefits of music education include a big amount of important aspects for children's development such as self-expression, as well as emotional expression and aesthetic enjoyment. The extrinsic music benefits for young children include fostering motor development, promoting cultural heritage, providing release of tension, teaching language development, using music as a carrier of information or as a cue for naptime, and using music to help teach other subjects such a reading or mathematics [17]. These characteristics support the idea to take music into focus in the creative design process.

When thinking especially the role of music as a trigger, there are lots of supporting theories for this role, especially for listening to music. Firstly, listening is considered as an important musical experience [13], [17]. According to Dura [13] musical experience is different from visual. Music is heard within the entire body [13]. According to him, music-listening experience is one of immersion in sound. Secondly, listening has a comprehensive character, children are dedicating to music, body and soul. According to Flohr [17] listening skills permeate all music activities [17]. Regarding research on music listening, it is important to note that when researching children it is often difficult to tell with certainty if a child is actively listening, but usually this can be determined by the child's movements or expressions [17]. Regarding the results that can be gained from children when listening to music, 
in a study of preschoolers it is argued that social interactions increased after music listening [19].

Even though our literature review presented three roles for music in connection to children and technology, instead of the whole categorization, we are going to focus only on the 'music and design' part of it. In this article the purpose is to concentrate on the roles of music in the design process and describe all the benefits we got during the design process when using music.

\section{Research Setting and Procedure}

The research setting is a multidisciplinary, international research project developing a music application for children, together with children. The researchers in the project have expertises in the information technology (IT) field, HCI research and/or music education. The target user groups of the music application are preschool (aged 3-6) and school-aged (6-12) children. The application in question is a learning application including games for singing, composing, instrument playing and improvisation.

The initial project objectives and the requirements for the music application were based on music education expertise. HCI experts entered the scene through evaluating the initial requirements and designs produced by the music educators, and through encouraging children to provide feedback as well as to create new ideas and designs for the application. Therefore, the HCI experts invited children into the design process as testers, informants and design partners [12]. This paper focuses on the design activities carried out during the project's first year of functioning in Finland, with the age group of 5-6 years old children. These activities were initially defined by a HCI research group in the University of Central Lancashire, the HCI research groups in Finland and UK both independently and collaboratively experimenting with and refining the activities (for more information, see [32]). The requirements for the activities came partly also from the music educators, who wished to gain insights and feedback related to their initial ideas and designs. The design activities examined in this paper were carried out in one nursery in Finland with the child group consisting of 9-13 5 and 6 years old children.

The design activities included the activities of "The Magic Music Toy", "If I were there I would play this" and "Cheers me up, puts me down" (for detailed description, see [32]). The "Magic Music Toy" activity allowed children to design their own magic music toy, first drawing it, and then producing a prototype of it with art craft materials. The activity aimed to understand children's concepts of music playing and to gather their ideas related to an ideal music toy. In the "Cheers me up, puts me down" activity, on the other hand, children listened to music and at the same time drew the feelings that the music triggered. This was done with two different music samples. The aim of this activity was to examine how children were able to relate music with emotions. This was requested by the music educators who planned to include a related feature to the music application. Finally, "If I were there I would play this" activity was about evaluating and inquiring how children relate music and places, which was also requested by the music educators since they planned to place different music samples to different landscapes in the music application. Children were asked to refine the original landscape pictures by adding instruments, sounds 
and any kind of general sensations they associated with the landscape. At the beginning of each workshop the researchers played and sang with the children and checked the situation of the day. Afterwards, the children were given the assignment. During the workshops the researchers walked around the room, discussing with the children and encouraging them if needed. At the end of the workshops, the children were interviewed.

All these design activities not only contributed to the specific research question mentioned in connection to them, but they all also produced a lot of useful and inspiring material to be utilized in the further application design: e.g. the children's drawings and prototypes provided highly useful information and ideas. The children were also continuously observed and interviewed during several occasions during these sessions, and their stories provided valuable insights for the research team.

All in all, during the design activities a lot of research data was gathered. The material was gathered by observing the children during the activities, by interviewing them during the work and afterwards, and by saving all the drawings and prototypes created by the children. The material includes video recordings, field notes made by the research team, photographs and the artifacts created by the children. In addition, the research team members were interviewed later on.

The data analysis concerning the meaning of music during the design process included a rich amount of material. The analysis process was data driven and inductive. The roles of music emerged from the data, i.e. there were no predefined hypotheses tested nor control groups involved to verify the effects of music, but instead this was an exploratory, data driven study of the roles of music. More rigorous, quantitative experiments can be carried out later on, based on and extending the results of this study. The data driven analysis process in this case started through collecting together all the information concerning sound and music and the equipments for producing sound from the video transcriptions, interviews, research notes and diaries, and children's productions including descriptions. The analysis involved expertise both in HCI and music education. All the data were connected together through careful analysis and transforming the findings into textual form and placing them into tables. The three roles of music inductively emerged during this process. Related to each role, supportive evidence was recorded. The results will be presented in the following empirical section.

\section{The Role of Music in the Design Process}

This section will demonstrate the meaning of music as context, as a trigger and as content in the design process. Although music and sound are important part of almost all software, the product being a music application increases the importance of music, especially in relation to designing content. The following descriptions will concentrate on illustrating the three different roles of music; therefore many details related to the whole design process in the examined research project in question are omitted. The first workshop was organized to have a general view about musical conceptions and children's musical world. It was like an inspiring start for the process. In the second workshop the purpose was to wake up the children to draw their sensations through carefully chosen music. In the third workshop, children were 
asked to fill up landscapes and at the same time to create musical material and soundscape for the user interface of the composition game part of the upcoming music application. Next the roles of music are discussed, as identified from these three workshops.

\subsection{Music as Context}

In this paper 'context' refers to the children's surrounding musical environment and to the concepts that clarify the meaning of music and music application among children. In a sense, it can be connected to the old claim of HCI research and practice to 'know the user and her context of use'; i.e. to understand the users' skills, knowledge and characteristics and the (physical, technical, social, organizational, cultural) context of use (e.g. [23]). In the first workshop the idea was to figure out the children's musical context and to find out their own music conceptions, preferences, abilities and knowledge, as well as to discover how they perceive the concept of "magic music toy": How their own magic music toy would look like? What kind of music and sounds would it produce? What would they like to do with it?

Sketching and making a prototype of the music toy was very inspirational work for the children. When observing their behavior (see e.g. [20]) they seemed to be enthusiastic with recycling materials and familiar with the topic of a music toy. The children also had clear ideas about their music toys and how they should look like. When asking the children questions about their sketches or devices they corrected erroneous impressions and had detailed explanations of the function and the structure. They were influenced by those instruments they had played or seen in the nursery or at home. Although the original form of the magic music toys was based on basic instruments like glockenspiel, drums or local instruments, the children added a lot of different kind of details and also ideas from the unmusical world like petrol and tank or the idea that instruments could walk or fly. Their ideas had even human faces and body combined with instruments like a man zither. Therefore, we claim that their ideas were much richer and imaginative than adults.

The children also had clear ideas on how to produce sound with the music toys; on the techniques how to play them and on the kinds of possibilities one has for producing sound. They had parts from wind instruments, string instruments or percussion. Although there were no keyboard instruments found in the children's prototypes, they used a lot of touchable buttons: "Over here you should give a whistle and at the same time you should press the buttons". They showed to the researchers how to play: "like this". Some of the children showed by voice what kind of sounds they produce. Children uttered different sound like: "pam pam, ti tit tii, tin tin". They described also very imaginative sounds such as white and black sounds coming out from zither. According to one boy some of the sounds are still secrets: "You can listen the most funny sounds of the world, but you can not know what kind of they are before you have played and heard them" Another boy added: "You can just guess them". The children had also clear ideas on what kind of equipments one needs for producing the sound. In addition to their hands and fingers, the children played with their feet and elbows, even guitar was played by heels. They had also additional equipments to produce the sound like a mallet. Those instruments were also designed for social playing: "the other person is whistling and other is pressing the buttons at the same 
time". Also Godeli and colleagues [19] have shown that music increases social behavior.

The children were also familiar with some musical concepts. They used during their work some concepts, which referred to volume (louder-softer), pitch (higherlower) and timbre, because of different sources of sound like strings, music pipes and drums. One example of timbre changes is in the black and white music of the zither. There was one girl who had a mechanism for producing sounds from different pitch levels and one boy who had a bass drum. Some children had clear volume buttons: "here you can put softer, and here louder". They had a conception about sound volumes "here you listen the sound and stop the sound, and here you can get the sounds quieter and here you can get them louder".

This workshop showed the children's ability to produce, by themselves, a logical completeness related to a music toy, which was constructed through a sketch, a prototype and the child's functional presentation. Children's imagination and playful stories about those constructions differ from those that would have been created by adults. It was very natural for the children to connect, for example, a musical instrument and an element from their daily life, like a starting motor. In their developmental stage it was also very natural to connect some human elements to the instruments, like a face, eyes, mouth or the whole body. Music offered an extra dimension for the work. Different kind of resounding methods and musical world inspired the children to create fictitious combinations of different elements. Their fantasy produced much more than the research group could note. According to a nursery maid this task has lived a long time in the games and plays in the nursery.

Musical context was inquired also in the second workshop related to emotions and music. When listening to music in the second workshop, the children drew a lot of familiar elements that came to their mid when listening to music. Children's intuitive visual representations of the listened music contained general contextual information about children's intuitive responses. Their drawings showed the musical world surrounding them. They drew what kind of instruments they had and played at home or in the nursery: "I drew a violin, because I have a violin at home" When interviewing the nursery staff, it was revealed that the children drew a lot of instruments they played in the nursery, like local instruments or rhythm instruments. The listening task showed also the children's ability to recognize different instruments from music. One six years old girl in particular recognized special rhythmic instruments like a quiro and a cabasa and blow instruments like a corn. In addition to real elements, the children also created imaginative elements through listening to music. Although some of the children had very imaginative, creative stories about their creations, most of the children draw, in addition to the instruments, familiar things for them like family members, home and nature.

\subsection{Music as a Trigger}

Trigger in this paper refers to an impulse, whose purpose is to support or shore up the design process, in this case children's creation through drawing. In the HCI field there seems to be a lack of research related to this area. Most references are from the educational and social studies. When describing music as a trigger, music is seen as a trigger for design. In this case music listening is intuitive and listening is like an 
experience [17] that the children are expressing mostly through drawing and unconsciously also for example through dancing.

In the second workshop on music and emotions, children listened to two different kinds of music samples and draw all the sensations that the music had given them and all the things that came to their mind. The music was chosen carefully, considering the developmental stage of the preschool children [17]. Even though children need to be considered as individuals, there are general principles concerning the developmental stages. For example, it has been argued that 5 to 6 years old children react to tempo changes and volume in music [17], [36], [44]. The first music sample was changing musical tempo from fast to slow, back to fast and slow again and so on. The other sample was changing from happy to sad music and back. All the children liked the music samples when asked about them: "music was fun".

All children were very keen on listening to music and drawing. When working with the children and when analyzing the video materials, in addition to settling down to listen, the children seemed to concentrate very well on drawing when listening to music. Music gave clear starting and ending points for the drawing task when compared to the drawing task that was carried out in the third workshop without music. The children started immediately and put their souls fast into creating the pictures. Engaging children's musical minds in an intuitive way seems to be a profitable way to produce material. The children also concentrated for a relatively long time to the task. When compared with the third workshop, in which the children were drawing on the prefilled landscape pictures, it seems that the children did not concentrate to drawing for so long time without music. When listening to music, the children worked intensively the whole time. They did not ask: "when we are going to stop?" They did not seem to be tired.

Like Flohr [17] describes, it is often difficult to tell with certainty if a child is actively listening, but usually this can be determined by the child's movements or expressions [17]. Although children were asked to sit down and to draw, one boy started to dance when he heard music. According to Dura [13], dance should be taken as an enticement to bodily listening. According to him, musical experience is different from visual, and music is heard within the entire body [13]. There were lots of examples found in the workshop authenticating those influences of music. Although children were asked to listen and to draw silently, there were also some children moving their feet with music or imitating the pipe sound through making different expressions with the mouth. One of the girls took immediately both hands in front of her mouth and like played a pipe with them when listening to march music. One of the boys slid his pen through a tunnel he had drawn at the same time when listening to the music. The movement of the music led one boy to draw a water wall and a bags throwing machine. Two of the children were drawing different windows. Perhaps this could also be interpreted through the rhythm of the music.

The workshop also showed that music supports children's creative imagination. Some drawings could be interpreted in a way that music gave some rhythm for those drawings, like for the machine which was throwing bags that was created when listening to march music. Two of the boys were drawing ways for the music: there was the water wall, the tunnel and a labyrinth. They also put sounds coming from the elements, like from the water wall or the machine: "machine is making the sound and the bags are flying and they join to the other picture" In addition, when being ready 
with drawing, as mentioned, one boy moved his pen through the tunnel when listening to the music. However, the music giving rhythm for the creations is a matter that requires more research. In addition, there is not that much evidence for understanding the influence of musical mode: the changes from happy to sad and back to happy. When listening to sad music some children drew also sad music like a sad violin. However, for most of the children sad music seemed to be happy. Most of them did not recognize the sad part of music. When asking children: "music was happy".

When having music as a trigger in the design process, individual creativity should be taken into consideration. It does not function in a given time. Although music gave also the ending point for the task, some children should have had more time for listening and drawing. Time refers to the moment-to-moment changes that occur within and between musical events, creating an experience of time as "lived or virtual time" as opposed to "real or clock time" [13]. In addition to time for drawing, there should be time for telling about those drawings and discussing then with adults. Music inspired some children not only to draw, but also to create imaginative stories. Often in the opinion of an adult those stories do not have very clear logic, but for the children the ideas are very clear and they just need time to explain them to the researchers in the discussion or in some kind of child's own presentation: "these are views, landscapes [shows a tractor and place where people are living], between them there is a water wall, which is at the same time a machine..." The boy was continuing his story through playing "smoke, put, put, put [showing with his pen the way of smoke coming out from the tractor pipe]" and he would have continued his story even for a longer time if he had been given the possibility. The children also liked to tell their stories to the researchers. Music was really like a trigger or impulse for creating material from their imagination.

\subsection{Music as Content}

Content means the musical substance, which is going to be contained in the given surrounding in the upcoming music application. The meaning of the content is significant in every design project. In this project the purpose was to produce suitable material for the composition part of the music application for preschoolers. Especially when designing a music game, music plays a big role during the process. The original requirements of the game design included three different landscapes: the jungle, the castle and the city. The children were asked directly to draw and add different kinds of sensations to the ready drawn landscape backgrounds. One important point of the task was to inquire the musical content; to note all the musical sounds children were combining with the pictures that were to act as user interface pictures in the upcoming music game.

Although the jungle is not a familiar surrounding for the children in Europe, they had well-defined opinions on what kind of sounds there should be. Some children liked silence, but most of them combined different nature sounds like wind, water, brooks, bird singing and trees to the picture. They added also instruments like a flute, a trumpet and a drum to the jungle. One of the girls heard ballet music in the jungle. They also described the character of the sound, how the sound was coming out: trees were vibrating, wind was blowing, and water and brook were producing sounds too. Animals were also very lively. The monkeys were shaking coconuts, and birds were 
singing. Animals were behaving like humans: "Jee, I got the banana". The children again created very imaginative picture combinations. One girl told that there was no sound in the picture, although a butterfly was carrying string instruments in her tail. There were also trumpets and flutes combined with the jungle.

In the castle and the city landscapes the sounds of the musical world were poorer, likely because of the children's ability to concentrate. Completing two pictures was fine for the preschool children, but three was too much. In the castle surrounding, a favorite source of sound was a ghost. They were hooting in almost all pictures. Children were putting themselves also in the picture. Humans were uttering sounds like: "iik, help, вӧо, иии, ооо". In the surrounding it was raining and thundering. There was also steam coming out from fire. Some of the children added also trumpet sounds to the picture. One of the boys thought the castle to be a church and he heard a priest speaking in a microphone and a lot of different instruments like a guitar and a cello.

In the city surrounding the most popular sound was the car. There were different kinds of cars whirring in the children's drawings. One boy had written "milk shop car". However, the children could not concentrate any more to the third picture. This was seen, for example, in the mixing of the ideas of the different pictures. For example, there were also coconuts in the city picture and those drawings were less detailed than before. Despite of this, the children found celebrating sounds and speaking people between apartment houses. There were also a thunderstorm and fire in the city. Some of the children found violin sounds and one of them told about secret sounds, but he could not tell what kind of sounds they were. Someone could hear "surr" in the picture.

This workshop showed the remarkable role of music in designing content, especially for a music game. Although this workshop did not include any live music, music and different sounds were an important part in those drawings. Especially all this information is important when the game designers are producing the preliminary sounds for the game. The children found natural sounds for the surroundings, like trees and brooks. They also found imaginative sounds like speaking animals and hooting ghosts. In addition to different instruments, there were a lot of interesting sources of sounds in the pictures like cars, animals, different kinds of people, even a singing flower, which had an influence on a color changing tree. There were also silent instruments, like those zithers in the tail of the butterfly.

In the first workshop the children also created sounds. They produced different kinds of sounds when creating and demonstrating their magic music toys. In addition, as mentioned, they told about secret, unheard sounds: according to one boy some of the sounds are secrets: "You can listen the most funny sounds of the world, but you can not know what kind of they are before you have played and heard them", another boy adding: "You can just guess them". These sentences bring again up the imaginative perspectives that adult designers probably would not think of.

\section{Discussion}

This paper examined the variety of roles music may have in the design process with children. Table 2 summarizes the results of our empirical examination. The results are 
presented according to the three roles of music we have identified, but also according to the insights gained through the use of music, categorized to two viewpoints: the insights gained related to the music application to be developed, and the insights gained in relation to children.

Table 2. The roles of music in the design process with children

\begin{tabular}{|c|c|c|c|}
\hline $\begin{array}{l}\text { Role of } \\
\text { Music }\end{array}$ & Context & Trigger & Content \\
\hline Application & $\begin{array}{l}\text {-appearance and } \\
\text { structure } \\
\text {-functionality } \\
\text {-sources of sound } \\
\text {-playing techniques } \\
\text { and additional tools } \\
\text { and instruments } \\
\text {-quality of sound and } \\
\text { timbre }\end{array}$ & $\begin{array}{l}\text {-extraordinary, surprising } \\
\text { viewpoints }\end{array}$ & $\begin{array}{l}\text {-sounds from the } \\
\text { imaginative and real } \\
\text { world } \\
\text {-imaginative } \\
\text { combinations of } \\
\text { sounds } \\
\text {-secret sounds } \\
\text {-silence }\end{array}$ \\
\hline Children & $\begin{array}{l}\text {-familiar music } \\
\text { applications, } \\
\text { instruments, sounds, } \\
\text { playing techniques } \\
\text {-musical concepts: } \\
\text { volume (louder-softer), } \\
\text { pitch (high-low), } \\
\text { timbre } \\
\text {-imaginative elements } \\
\text { and combinations from } \\
\text { the children's world } \\
\text { - important issues in } \\
\text { the children's life (in } \\
\text { addition to music) } \\
\text { - social behavior } \\
\text { related to music }\end{array}$ & $\begin{array}{l}\text {-giving information about } \\
\text { children's intuitive } \\
\text { responses } \\
\text {-enabling musical } \\
\text { experience } \\
\text {-showing expressions, in } \\
\text { addition to drawing, } \\
\text { through moving and } \\
\text { discussing } \\
\text { - supporting children's } \\
\text { developmental stage and } \\
\text { imagination } \\
\text { - supporting } \\
\text { concentration and } \\
\text { intensive working } \\
\text { - giving structure for the } \\
\text { task }\end{array}$ & $\begin{array}{l}\text { - ability to create } \\
\text { and describe sounds } \\
\text { to a given } \\
\text { surrounding } \\
\text { - ability to create } \\
\text { imaginative musical } \\
\text { worlds } \\
\text { - ability to express } \\
\text { clear opinions } \\
\text { - problems in } \\
\text { concentrating for } \\
\text { very long }\end{array}$ \\
\hline
\end{tabular}

Through the use of music the researchers gained inspirational background information related to children's favorite music toys and applications, and directly utilizable musical material for the music application as well as useful, inspiring material for the user interface design. One interesting detail in the results is the issue of secret sounds that even the children themselves had not heard or created yet. Clearly, a lot can be learned from children when designing together with them, not only music applications, but different kinds of applications in general. Related to the children, the researchers gained a lot of insights of their musical world, of the concepts they use, of their imagination related to music, and of their preferences, abilities and knowledge. The results revealed the importance of musical experience also in the context of IT design. It aroused children's sensations and imagination. In addition, the researchers learned that the children were able to create imaginative 
musical worlds and to create and describe sounds to a given surrounding. They were able to refine the pre-defined musical landscapes and to express their opinions about the musical content. It was also learned that their ability to concentrate is quite limited, but music acting as a trigger may diminish, to a certain extent, this problem.

The workshops carried out also had a clear impact on the design of the application (see also [32]). All the findings and ideas that could be somehow utilized in the application design were gathered from the research material, and discussed with the developers and with the persons responsible for the application design. It was revealed that the material collected while working with the children contained ideas regarding the structure of the application and the design of certain icons, and even some pictures that could be directly used in the user interface design. Paper prototypes were afterwards built, utilizing numerous ideas gained from these workshops, and evaluated together with children. Thereafter, the developers built functional prototypes relying on those evaluated designs. Also the actual implemented application still contains ideas derived from children during the workshops.

All in all, the different roles of music we identified demonstrate numerous possibilities for using music in design workshops and show the usefulness of music in the collaborative design process with children. Especially music should be utilized while designing music applications. However, we argue that HCI research, altogether, should be broadened to utilize music in more varied forms, relying on the already established interdisciplinary results related to music. So far, HCI research has focused on the design of interactive products emphasizing their usability, fun and learning related aspects. The numerous design methods created for working with children within the HCI field do not pay any attention to the use of music. However, important to note is that in our research project there are also music education specialists involved. The utilization of music in the design process requires the participation of the domain specialists related to music. However, also HCI researchers played a substantive part in organizing the workshops and in analyzing the results. We recommend multidisciplinary collaboration for the researchers interested in utilizing music in their design sessions.

We bring up four important matters connected to using music in HCI research. Firstly, music constitutes a big part of the life and education of children. Music gives strength for a child and his/her actions and development. Music clearly belongs to the young child's life, like Flohr [17] describes. The meaning of sound and music comes up already in the prenatal phase of human being [17]. Developmental psychologists such as Piaget [36] and Vygotsky [44] underline the value of music as a supporting element in children's development. Music is a natural part of children's life and education, like this research connected to the different tasks concerning music has also shown. Music is one of the important elements among other subjects such as art and drama in nurseries. It is very easy and artless for a child to immerse in the world of music and to show her expertise in different tasks, such as in those described in this paper.

Secondly, music is comprehensive and it interacts with different levels of sensation. Music also penetrates easily through human being to the stage of emotions, like several specialists [14], [15], [34], [37], [38] have confirmed in their studies. Through that characteristic it is easier to understand children's behaviour when listening to music. Listening is an experience [13], [17], which is different from 
visual. Music is heard within the entire body. Children's concentration, movements, dancing or spontaneous reacting to the sounds or music illustrates the multidimensionality of music. Through music it is possible to reach something, which otherwise would not be possible.

Thirdly, music enriches children's creations and there is a possibility to gain surprising results. Like several researchers [14], [15], [34], [37], [38] have discovered, music supports children's expressions and for example aesthetic enjoyment. Music supports children's creative process and gives them inspiration and new, imaginative ideas. From the point of view of design, especially the listening and drawing exercise with music acting as a trigger brought up new, interesting ideas.

Fourthly, music inspires and enables children to participate in a design process in a natural way. According to Flohr [17] extrinsic musical benefits for young children include using music to help teach other subject such as reading or mathematics. It is easy to subscribe to this and to pronounce the idea of music as an important supporter of design process with children, too. Music provides a natural way for a child to approach new issues such as design. Therefore, music can be used for making it easier for children to engage in technology design.

Altogether, this study offers some confirmation to the previously presented theories and demonstrates the usefulness of music in the design process with children. The major arguments supporting our findings concerning the usefulness of music in the design process could be summarized as follows:

- music is a natural part of children's life and education

- $\quad$ music is comprehensive and has an influence on all sensations

- music enriches and supports children's creations

- $\quad$ music inspires and supports children's participation

\section{Conclusions}

This paper reviewed the role of music in the design process with children. When taking the developmental stage of the children into consideration, we claim that music and other art based methods should play a significant role in designing with children. A review of the related research was carried out. Based on the review it was argued that the role of music in the design process has been neglected in the research on music, technology and children, while there is a lot of meaningful research in the areas of social and educational studies carried out. These studies indicate that music can and should appear in the design process in many different forms. The review of the literature on music, technology and children showed that the research has concentrated on technological products and technological needs of special education, mentioning music also as an important part of media. We, instead, examined the versatile role of music during the design process with preschool children in three different workshops. We identified three different roles for music: a contextual role, music as a trigger and music as content. The contextual role offers significant background information for the design process and insights into the world of the participating children. It also gives a preliminary conception about children's music and the elements of the music application. The role as a trigger shows the importance 
of musical experience, in this case of music listening, in the creative process like designing. It helps to arouse children's sensations and gives information about intuitive responses. Because of the support for creativity it is possible to get extraordinary results for the design process. The meaning of music as content increases especially when designing a music application. Children have clear opinions about musical content and they can create both real and imaginative sounds.

Regarding the practical implications of this study, we claim that other researchers interested in designing with children can now start planning to use music as part of their design sessions. Similar kinds of design sessions as the ones described in this paper can be organized, but the three roles of music can be integrated into other kinds of design sessions as well. Musical context can be inquired through interviewing, observing, drawing and prototyping, as has been demonstrated in this paper, in line with the results presented e.g. by Druin [11]. Treating music in the contextual role enabled the research team to gain information about children's understanding about different kinds of instruments, musical applications and music toys - about their structure and functionality - and about playing techniques and musical concepts they use. This all provides highly useful information for the adult designers making decisions related to the future music application: related to its structure, functions, appearance and content. The results of this study also indicate that preschool children are fully capable to sketch, build and present imaginative musical prototypes.

In addition, this study shows the usefulness of using music as a trigger. The benefits of this are connected to the imaginative results gained and to the ways music inspired children and supported their concentration and intensive working. Music samples played in the design session also gave structure for the task. Music can be integrated into numerous kinds of creative workshops organized with children. However, we recommend multidisciplinary cooperation in planning these sessions. Music education expertise was valuable in our research project especially during this phase.

Furthermore, we recommend also other researchers to invite children to create, together with adult designers, the content of the application, i.e. to act as design partners [12]. In our session children created imaginative musical worlds and brought up also surprising perspectives (e.g. the secret sounds). They were capable to create and describe sounds to the predefined musical landscapes and well equipped to express their opinions. However, related to this session it was also noticed that the preschool children's ability to concentrate is limited, which should be taken into account by all researchers working with young children.

There are several limitations connected to this study. More extensive presentation of the whole development process as well as of the research material gathered during the three workshops would bring up more varied picture of this field and give to the reader more possibilities to apply these ideas in practical design sessions with children. On the basis of this research we highlight the importance of charting the different roles of music and its several utilization possibilities. It is useful to specify the character of different roles and the methods used with children in design in practise. In the future it is worthwhile to continue this kind of work and to describe the different possibilities of music, not only as a listening experience, but also as a singing, composing and improvising experience. 
Finally we conclude that in order to create meaningful, inspiring design experiences for children, designers in the HCI area should take into consideration the meanings of music. This area has many meaningful and creative possibilities to utilize music. This article shows a way, through music, towards more creative, inspiring design process where children are active participants designing the target application.

Acknowledgements. This research has received funding from the European Community's Seventh Framework Programme (FP7/2007-2013) under grant agreement $n^{\circ}$ 22456. We thank the UMSIC consortium for enabling this work. We also thank SILKKIUIKKU -project group for carrying out the design activities in the nursery, as well as the children and teachers from the nursery for contributing to the design sessions.

\section{References}

1. Akiyama, Y., Oore, S.: PlaceAndPlay: a digital tool for children to create and record music. In: CHI 2008: Proceeding of the twenty-sixth annual SIGCHI conference on Human factors in computing, pp. 735-738. ACM Press, New York (2008)

2. Aucouturier, J., Ikegami, T.: The Illusion of Agency: Two Engineering Approaches to Compromise Autonomy and Reactivity in an Artificial System. Adaptive Behavior 17(5), 402-420 (2009)

3. Bar-Ilan, J., Belous, Y.: Children as architects of web directories: An exploratory study. Source: Journal Of The American Society for Information Science and Technology 58(6), 895-907 (2007)

4. Beck, L.: Nurturing your child with music: How sound awareness creates happy, smart, and confident children. Library Journal 125(4), 118-118 (2000)

5. Benveniste, S., Jouvelot, P., Lecourt, E., Michel, R.: Designing wiiimprovisation for mediation in group music therapy with suffering from behavioral disorders. In: Proceedings of the 8th International Conference on Interaction Design and Children, IDC 2009, pp. 18-26. ACM Press, Como (2009)

6. Berry, R., Makino, M., Hikawa, N., Suzuki, M., Inoue, N.: Tunes on the table. Multimedia Systems 11(3), 280-289 (2006)

7. Bobick, A.F., Intille, S.S., Davis, J.W., Baird, F., Pinhanez, C.S., Campbell, L.W., Ivanov, Y.A., Schutte, A., Wilson, A.: The KidsRoom: A perceptually-based interactive and immersive story environment. Presence-Teleoperators and Virtual Environments 8(4), 369-393 (1999)

8. Bresler, L.: Teachers as Audiences: Exploring Educational and Musical Values in Youth Performances. Journal of New Music Research 39(2), 135-145 (2010)

9. Druin, A.: Place called childhood. Interactions 2(5), 12-15 (1996)

10. Druin, A., Stewart, J., Proft, D., Bedeson, B., Hollan, J.: KidPad: a design collaboration between children, technologists, and educators. In: Proceedings of the SIGGHI Conference on Human Factors in Computing Systems, Atlanta, Georgia, United States, March 22-27, pp. 463-470 (1997)

11. Druin, A.: Cooperative inquiry: Developing new technologies for children with children. In: Proceedings of CHI 1999, pp. 1-25. ACM Press, New York (1999)

12. Druin, A.: The Role of Children in the Design of New Technology. Behaviour and Information Technology 21(1), 1-25 (2002) 
13. Dura, M.: The Phenomenology of the Music-Listening Experience. Arts Education Policy Review 107(3), 25-32 (2006)

14. Elliott, D.J.: Musicing, Listening, and Musical Understanding. Contributions to Music Education (20), 64-83 (1993)

15. Elliott, D.J.: Putting Matters in Perspective: Reflections on a New Philosophy. Quarterly Journal of Music Teaching and Learning 7, 20-35 (1997)

16. Fischer, T., Lau, W.: Marble track music sequencers for children. In: IDC 2006 Proceedings of the 2006 Conference on Interaction Design and Children, pp. 141-144 (2006)

17. Flohr, J.W.: The musical lives of young children. Pearson Prentice Hall Music Education, Upper. Saddle River (2005)

18. Guha, M., Druin, A., Chipman, G., Fails, J., Simms, S., Farber, A.: Working with Young Children as Technology Design Partners. Communications of the ACM 48(1), 39-42 (2004)

19. Godeli, M.R., Santana, P.R., Souza, V.H., Marquetti, G.P.: Influence of background music on confused and agitated elderly patients. Archives of Psychiatric Nursing 7, 284-291 (1996)

20. Hanna, L., Risden, K., Alexander, K.: Guidelines for Usability testing with Children. interaction, pp. 9-14 (September + October 1997)

21. Harris, B., Summa-Chadwick, M.: A computerized system for Neurologic Music Therapy. Journal of Computing Sciences in Colleges 21(2), 250-257 (2005)

22. Hartnett, J., Lin, P., Ortiz, L., Tabas, L.: A responsive and persuasive audio device to stimulate exercise and fitness in children. In: CHI 2006 Extended Abstracts on Human Factors in Computing Systems, pp. 1837-1842 (2006)

23. ISO 13407: Human-centered design processes for interactive systems, International Standard (1999)

24. Jennings, K.: Hyperscore: A Case Study in Computer Mediated music Composition. Education and Information Technologies 10(3) (2005)

25. Jentschke, S., Koelsch, S., Sallat, S., Friederici, A.: Children with specific language impairment also show impairment of music-syntactic processing. Journal of Cognitive Neuroscience 20(11) (2008)

26. Koelsch, S., Grossmann, T., Günter, T., Hahne, A., Scröger, E., Friederici, A.: Children Processing Music: Electric Brain Responses Reveal Musical Competence and Gender Differencies. Jourmal of Cognitive Neuroscience 15(5) (2003)

27. Li, W.: Musical box: draw it yourself. In: IDC 2010 Proceedings of the 9th International Conference on Interaction Design and Children (2010)

28. Lugmayr, A., Risse, T., Stockleben, B., Laurila, K., Kaario, J.: Semantic ambient mediaan introduction Source: Multimedia Tools and Applications, vol. 44(3), pp. 337-359 (2009)

29. Magne, C., Schön, D., Besson, M.: Musician Children Detect Pitch Violations in Both Music and Language Better than Nonmusician Children: behavioral and Electrophysiological Approaches. Journal of Cognitive Neuroscience 18(2) (2006)

30. Markopolous, P., Bekker, B.: On the assessment of usability testing methods for children. Interacting with computers 15, 227-243 (2003)

31. Markopoulos, P., Read, J., MacFarlane, S., Höysniemi, J.: Evaluating Interactive Products for and with Children. Morgan Kaufmann, San Francisco (2008)

32. Mazzone, E., Iivari, N., Tikkanen, R., Read, J., Beale, R.: Considering context, content, management, and engagement in design activities with children. In: IDC 2010 Proceedings of the 9th International Conference on Interaction Design and Children, pp. 108-117 (2010) 
33. McKnight, L., Read, J.: Designing the 'record' button: Using children's understanding of icons to inform the design of a musical interface. In: IDC 2009, pp. 258-261. ACM Press, Como (2009)

34. Merriam, A.P.: The Anthropology of Music. Northwestern University Press, Evanston (1964)

35. Miura, S., Sugimoto, M.: Supporting children's rhythm learning using vibration devices. In: Proc. of CHI, pp. 1127-1132. ACM, New York (2006)

36. Piaget, J.: Play, Dreams, and Imitation in Childhood. Norton, New York (1962)

37. Reimer, B.: A philosophy of music education. Nortwestern University, USA (1970/1989)

38. Reimer, B. (ed.): World Musics and Music Education: Facing the Issues. Reston, VA.MENC - The National Association for Music Education (2002)

39. Reynolds, N.: The Computer as Scaffold, Tool and Data Collector: Children Composing with Computers. Education and Information Technologies 10(3) (2005)

40. Rosenbaum, E., Silver, J.: Singing Fingers: fingerpainting with sound. In: IDC 2010 Proceedings of the 9th International Conference on Interaction Design and Children (2010)

41. Rusinek, G., Rincon, C.: Attending Musical Performances: Teachers' and Students' Expectations and Experiences at a Youth Programme in Madrid. Journal of New Music Research 39(2), 147-158 (2010)

42. Scaife, M., Rogers, Y.: Kids as informants: Telling us what we didn't know or confirming what we knew already? In: Druin, A. (ed.) The Design of Children's Technology, pp. 2750. Morgan Kaufmann, San Francisco (1999)

43. Upitis, R.: Technology And Music - An Intertwining Dance. Computers \& Education 18(1-3), 243-250 (1992)

44. Vygotsky: On the Zone of Proximal Development. In: Mind in Society (Trans. M. Cole), pp. 84-91. Harvard University Press, Cambridge (1978)

45. Weinberg, G., Orth, M., Russo, P.: The embroidered musical ball: a squeezable instrument for expressive performance. In: CHI 2000 Extended Abstracts on Human Factors in Computing Systems (2000)

46. Zigelbaum, J., Milner, A., Desai, B., Ishii, H.: BodyBeats: whole-body, musical interfaces for children (2006) 